\section{Electronic Records Management Strategies by Government Agencies in Kenya}

\author{
Jonathan Limo', Tom Kwanya' ${ }^{2}$, Sally Chepchirchir ${ }^{1}$
}

Karatina University ${ }^{1}$

The Technical University of Kenya ${ }^{2}$

\section{Abstract}

Background of the study: With the advancement in technology, government agencies generate, receive or use records in electronic formats. There is need to develop appropriate strategies to manage these electronic records effectively. An electronic records management strategy must be aligned to the agency's legal mandate as well as reflect best records management practices and technological options.

Purpose: This chapter explores the extent to which government agencies in Kenya apply electronic records management strategies in regard to legal framework, long-term preservation, metadata, file naming and file formats, and digital media storage.

Method: Additional data was collected through a review of relevant literature. The data was analysed and presented using descriptive statistics.

Findings: The findings indicate that the Government of Kenya recognises electronic records as valuable. The study leading to this chapter was conducted as an online survey through which data was collected from records managers working in 90 government agencies who are members of the Network of Library \& Information Professionals in Kenya. The link to the online questionnaire, hosted on Google Forms, was circulated through the network's administrator. 38 officers successfully filled the forms.

Conclusion: It has developed and deployed several policies and legislation to enhance the management and use of electronic records for posterity. However, the government lacks facilitative structural and budgetary provisions to implement these effectively.

Keywords: Archiving, electronic records, file formats, metadata, preservation, government agencies, Kenya.
Paper Type:

Literature Review

Submitted 26 March 2019

Accepted 30 April 2019

Online 30 September 2019

* Correspondence:
Jonathan Limo
E-mail:
jlimo@karu.ac.ke 


\section{Introduction}

Bellardo and Carlin (1992) define a record as a document created or received and maintained by an agency, organisation, or individual in the pursuance of legal obligations or in the transaction of business. Splindler (2009) avers that an electronic record is a form of information produced in the course of an event or a routine activity by an individual or organisation. Shepherd (1994) explains that electronic records are stored in the form of electronic signals on magnetic, optical and other media. Bellardo and Carlin (1992) concur that electronic records are records which are stored in electronic media. The Government of Kenya (2009) defines electronic records as any combination of text, graphics, data, audio, pictorial, or other information representation in digital form that is created, modified, maintained, archived, retrieved, or distributed by a digital information system. For a document to be considered as a record, its context, content and structure should enable it to provide evidence of a transaction regardless of its format or medium of storage. The European Commission (2001) explains that although a record can exist in more than one document, it should never change; it must be fixed.

Debate is on-going on the distinction between electronic record and electronic information or data. Although there is no end in sight of this debate, Splindler (2009) explains that electronic records require both context and content to successfully document an event, activity or business transaction. Most of electronic information lack requisite context to enable them to be relied upon as an enduring evidence of transactions or events. Duranti and MacNeil (1996) hold the view that electronic records consist of a physical medium which carries the message; form which encompasses the rules of representation facilitating the communication of the message; persons required to act on the basis of the record; action which originates the record as a means of creating, maintaining, changing, or extinguishing situations; contextual framework in which the action takes place; archival bond that links each record to the previous and subsequent one and to all those which participate in the same activity; and content or message that the record is intended to convey. They point out, however, that these components are not inextricably joined together as the case is in traditional records. Conversely, the parts exist separately and can be managed independently unless they are intentionally tied together for the purpose of ensuring the creation of reliable records and the preservation of authentic records. Splindler (2009) adds that electronic records may have been created in digital format or may be converted from hard copy to soft copy using myriad approaches and tools. He further explains that electronic records may consist of digital images, audio files, geographic information systems files, word-processed files, and email among other documents. Some electronic records, he observes, exist in single file formats while others combine several formats.

According to Sprehe (2002), effective records management enables organisations to conduct business in an orderly, efficient, and accountable manner; deliver services consistently and equitably; document policies, decisions, and outcomes to stakeholders and regulators; meet legislative and regulatory requirements, including audits; protect self in litigation; function in a financially and ethically accountable manner; protect corporate interests as well as the rights of employees, clients, and other stakeholders; provide continuity of operations in an emergency or disaster; and maintain its corporate and institutional memory. Sprehe (2005) argues that over the years the emphasis of records management seems to have shifted to roles such as documenting policies, decisions, and outcomes to stakeholders and regulators; meeting legislative and regulatory requirements, including audits; protecting enterprise in litigation; functioning in a financially and ethically accountable manner; protecting enterprise interests as well as the rights of employees, clients, and other stakeholders; providing continuity of operations in an emergency or disaster; and maintaining documented institutional memory in case of investigation or litigation.

McLeod and Hare (2005) argue that electronic records management is a vital but complicated affair involving multiple functions and strategies. Gilliland-Swetland (2006) describes electronic records management as the practical management of electronic records, from birth to final disposition, and to theoretical and applied research relating to the nature, management, and use of those records. Shepherd (1994) suggests that effective electronic records management encompasses management, organisational, technical and legal perspectives. She explains that management and organisational issues that arise in 
electronic records management are organisational structure, intellectual controls over records, and intraorganisational collaboration. Splindler (2009) explains that some of the factors which influence electronic records preservation include storage media; software and document encoding issues; human error and vandalism; backups and snapshots; as well as metadata and retention of context. Johnston and Bowen (2005) suggest that the five principles that influence the success of electronic document and records management systems are: 1) the system must be designed with the input of the stakeholders such as organisational policy makers and users; 2) the system must be integrated with the other processes of the organisation to ensure a seamless interoperability; (3) the system should not revolve around the records managers whose role should be to educate, advise and support the users; 4) there is need for a continuum model which encompasses both documents and records and gives clearer benefits than separate document and record lifecycles; and 5) there is need to embrace flexibility since there is no single "magic bullet" to solve information management problems.

Electronic records are becoming popular because they yield many benefits to organisations compared to paper-based records. The benefits include reliable backups, increased security and control, enhanced collaboration, multiple simultaneous use, increased timeliness, reduced archiving costs, improved version control, no degradation due to wear and tear, enhanced access and use of records including remotely, improved efficiency through effective filing, long-term retrievability because there are no file losses, enhanced searching capability, improved distribution capacity, consistent content, builtin regulatory compliance, saves on labour requirements, enhanced records classification and control, increased resilience in times of disaster, reduced vulnerability to vandalism, improved records integrity, multimedia support, and improved task management. In spite of the benefits, working with electronic records requires huge initial investments in technological infrastructure, enhanced information technology skills, and costly purchase of software. Electronic records are also vulnerable to unauthorised access and tamper through hacking, systems crash or downtime, as well as technological obsolescence. Electronic records in the clouds may create challenges associated with ownership, custody and retention because they are not under the direct control of the organisation.

\section{Literature Review}

The significance of effective records management in governments has risen in the recent past with the growing popularity of open governance, electronic government as well as the clamour for freedom of information legislation. Thus, most governments the world over have embraced records management as an important function towards the achievement of their constitutional mandates. Governance and records management professionals have come to accept the fact that a reliable and accessible evidence-base is critical to the realisation of open government (Thurston, 2015). Indeed, reliable records are the foundation upon which the right to information and open data can be anchored. Whereas records management in and of itself cannot achieve openness, it is impossible to make any meaningful progress in this regard without it. Records support day-to-day government operations and provide evidence of policies, actions, transactions, expenditure, precedents, rights and entitlements. Weak records controls result in an ad hoc, potentially misleading national evidence-base that opens opportunities for manipulation, corruption and fraud; weakens citizens' ability to claim fair rights and entitlements; undermines the ability to plan and monitor policies and services; and makes it difficult to open information effectively.

Several countries have taken specific steps to mainstream records management in their government functions. According to Open Government Partnership (2015), Canada has developed a policy making it every government officer's responsibility to appropriately manage information in all forms and formats. Thus, records management is integrated in all government business thereby making it possible for information to be used and recognised as a valuable asset. Integrating information management requirements with technology planning ensures that digital information is accessible, shareable, and usable over time and through technological change. Other governments which have taken steps to enhance records management in their practices include Finland which has domesticated the right of access to information principles; the United Kingdom has developed a code on records management to 
support its freedom of information legislation; India has developed a centre of excellence for digital preservation; Malaysia has developed a set of specifications for electronic records management systems; Norway has developed standardised metadata requirements for records management; Scotland has developed a data strategy for the public sector governed by a data linkage framework; Sierra Leone has developed a national records control regime; Sweden has developed common specifications to support government agencies in transferring digital records between different records management systems and agencies; Australia has adopted a digital transition policy; Tanzania has empowered its national archives to set standards for managing public records; while the United States has developed a comprehensive set of records management instructions for federal employees and contractors.

According to Thurston (2015), governments can accrue several benefits from electronic records. Some of these benefits include the following:

- The public can have confidence in the credibility, authenticity, and integrity of the information, and public sector agencies can use them effectively for planning and monitoring programs, activities, and expenditure.

- It is possible to rapidly trace, relate, and compare policies, decisions, actions, and expenditure accurately over long periods of time as a basis for an informed and socially just society.

- Accountability and transparency are safeguarded. An audit trail of any changes or unauthorised use of the records makes it possible to detect and trace corruption.

- Records can be opened to the public systematically and privacy rights can be protected. Any restriction on opening records can be justified and documented.

- Right to information requests can be met rapidly and reliably. Documents can be tagged when there is a legal restriction on publication.

- Records can be migrated to new formats and software and hardware environments as necessary.

- Standardised interoperability rules can be applied effectively, making it possible to interface dispersed information systems, such as document management systems, accounting systems, or information systems specific to an organisation's activities, and to reuse information.

- Records can be securely and systematically extracted from diverse digital systems and transferred to long-term digital custody, where they can continue to meet legal, administrative, fiscal, or other evidentiary needs through time.

- Information loss is minimised. The high risk of holding digital records outside secure managed storage decreases.

Thurston (2015) states that Nordic countries have made relatively good progress in managing public digital records. She argues that this is because these countries are committed to openness and exhibit unique socio-justice value systems. She explains that Nordic countries have achieved this by developing and implementing clear objectives and targets on digital records as well as establishing effective quality control systems which is an interface between interconnected laws, standards, well-defined metadata architectures, and technology systems specifying mandatory requirements.

Governments experience several challenges in their electronic records management efforts. Some of these include inadequate policies and legislation; lack of clear standards; poor interoperability and compatibility between systems; inadequate technological infrastructure; lack of political goodwill; inadequate human resources; poor definition of roles, responsibilities and obligations in relation to the management of multi-agency records; as well as lack of trust between different government agencies and ministries.

Open Government Partnership (2015) suggests that governments should consider the following to ensure their records management initiatives succeed: 1) ensure that there is a law or a harmonised set of laws for managing records needed as evidence for national development and accountability, and establish a public authority as the lead government records management; 2) establish a central digital repository to provide lasting access to government records and data; 3 ) establish a means of relating quality assurance for public sector digital records and public sector datasets; 4) establish and implement standardised requirements for managing digital records and metadata across government in line with international good 
practice standards; 5) include records management requirements in the specification criteria for new information technology systems and upgrades; 6) strengthen the capacity of records management professionals to meet the challenges of managing records in all forms and formats; as well as 7) use the findings of the gap analysis to develop a government-wide policy on records management in line with goals for open government and sustainable development, including digital governance, right to information and open data.

\section{Contextual framework}

Kenya is a republic with a national government consisting of the executive headed by an elected president; legislature headed by the speaker of the national assembly; and judiciary led by the chief justice. Since 2013, the country also has 47 devolved government units called counties headed by an elected governor. Each of the counties also has a legislative assembly of ward representatives. Government functions are executed through ministries and other agencies.

The management of public records in Kenya is governed by the Public Archives and Documentation Service Act, Cap 19, 1965 (Revised 2003) of the laws of Kenya. Similarly, there are several rules, regulations, and circulars issued by different agencies to guide the management of records. The Government of Kenya (GOK) has also developed a specific policy on records management (GOK, 2009). According to the policy, the government asserts that records are a source of information and as such are a basic resource which plays a vital role in the development of the country. The policy recognises the fact that records play a key role in the preservation of the country's identity and also contribute significantly to the realisation of good governance. The government asserts in the policy that records ensure that the government has documented evidence of its own activities on which it can base its decisions. Thus, properly managed records contribute to policy formulation leading to faster decision making processes which directly impact on efficiency and effectiveness of service delivery in organisations. The government acknowledges that a nation's ability to function effectively and give account of its actions can therefore be negated if sound records management principles are not applied. Furthermore, records are an important corporate asset that must be accorded the same care as other government resources such as finance and personnel.

Apart from the Public Archives and Documentation Service Act, Cap 19, 1965 (Revised 2003), there are other related Acts, subsidiary rules, regulations and circulars. These include the Records Disposal Act, Cap. 14, 1962; Anti-Corruption and Economic Crimes Act, 2003; Public Officer Ethics Act, 2003; Statistics Act, 2006; Public Procurement and Disposal Act, 2005; Public Audit Act, 2003; Government Land Act, Cap. 280, 1915; Registered Land Act, Cap. 300, 1963; Value Added Tax Act, Cap. 476, 1990; Financial Management Act, 2004; Directorate of National Intelligence Service Act, 1998; the Evidence Act, Cap. 80, 1977 (Revised 1989); Kenya Information and Communication Act, No. 2 of 1998 (Revised 2009); Freedom of Information 2007; Government Financial Regulations and Procedures, Chapter, 23 Section 3 - 5; Ministry of State for Public Service - Personnel letter No. 1/2008 (DPM.12/6A Vol. 1 (71); ISO 15489 (2001): Information and Documentation - Records Management; Kenya Police Standing Orders, 2001; Government of Kenya Security Manual, 2005; and departmental records retention schedules.

The government policy on public records management clearly states that all public organisations shall design systems and procedures to ensure that accurate and reliable records are created and maintained. The Government of Kenya's policy on electronic records asserts that electronic records generated or received by public officers in the course of official business are public records. As such as records of government agencies, electronic records, like records in other formats, are subject to statutory and regulatory requirements. To maintain integrity, accuracy and authenticity of electronic records, public offices shall ensure that public officers at all levels are provided with adequate skills and competencies in the management of electronic records; electronic records are managed effectively as part of a comprehensive records management programme; electronic records are maintained in electronic form where appropriate; electronic records are maintained in reliable recordkeeping systems; maintenance and 
provision of authorised access to electronic archives is a shared responsibility between the records creators and Kenya National Archives and Documentation Service; electronic records which may be required in future as evidence shall comply with metadata requirements, which should include content, context and structure; and practical strategies are taken for the long-term preservation of electronic records in view of technological obsolescence.

Despite the efforts made by the government, the state of records management in Kenya still remains a challenge due to lack of standardised practices and procedures. According to Mnjama (2003), public records in Kenya are not managed effectively. He attributes this situation to failure by senior government officers to establish acceptable records management goals and practices; hire competent records management staff; provide adequate records storage facilities; encourage professional training in archives and records management; provide financial and administrative support to the records management function; closely supervise archives and records management tasks; and implement recommendations on effective management of records.

\section{Rationale and methodology of study}

Although the government's policy is clear on the need to manage electronic records, it does not provide details on the strategies which public agencies can use to realise this. Consequently, Sanya (2015) argues that the management of public records in Kenya still face several challenges including poor documentation of instructions and actions as most officers rely on oral communication; staff demotivation and high turnover; poor coordination and collaboration; inadequate resources; lack of standardisation of records formats; deterioration of existing infrastructure; and ad hoc records disposal. These challenges are likely to persist in spite of the policy. There is need for an analysis of strategies which public organisations can apply to enhance the management of electronic records they create or receive.

This chapter explores the extent to which government agencies in Kenya apply electronic records management strategies in regard to legal framework, long-term preservation, metadata, file naming and file formats, and digital media storage. The study leading to this chapter was conducted as an online survey through which data was collected from records managers in 94 government agencies (see Appendix 1) who are members of the Network of Library \& Information Professionals in Kenya. The link to the online questionnaire, hosted on Google Forms, was circulated through the network's administrator. 38 officers successfully filled the forms. Additional data was collected through a review of relevant literature. The data was analysed and presented using descriptive statistics.

\section{Discussion}

The study sought to find out the strategies applied by government agencies in Kenya to manage electronic records. As explained earlier, respondents were chosen from 94 government agencies in the country. Records managers made up $25(65.8 \%)$ of the respondents while librarians were $9(23.7 \%)$. $2(5.2 \%)$ respondents indicated their positions as accountant and procurement officer. Three respondents did not indicate their positions. The highest qualification of the respondents was an important factor so as to get their level of understanding of the subject. Bachelor's degree qualification was the highest at $22(57.9 \%)$, masters $8(21.1 \%)$, diploma $6(15.8 \%)$ and one respondent with a doctorate.

The study also investigated the size of the agency by the number of employees. This is important because it gives a hint on the management style and, maybe, automation in the agency. The size of the agency with less than 100 employees made up 2(5.4\%) of the respondents; $101-1000$ employees 19(51\%); and over 1000 employees 16(43.2\%). The study also sought to establish the type of electronic records managed by the agencies as official records. 26(68.4\%) of the respondents indicated that they managed e-mail messages and word-processed documents; 26(68.4\%) managed spread-sheets; 24(63.2\%) digital images; while 24(63.2\%) managed databases.

5.1 Legal framework

The researchers intended to establish the understanding of laws that guide the management of electronic records by record managers. 28(73.6\%) of the respondents said they understood Public 
Archives and Documentation Service Act, Cap. 19, 1965 (Revised 2003). Public Procurement and Disposal Act, 2005 24(63.1\%) of the respondents, Financial Management Act, 2004 10(26.3\%) of the respondents, Government Financial Regulations and Procedures, Chapter 23, Section $3-5$ 9(23.6\%) of the respondents, Ministry of State for Public Service - Personnel Letter No. 1/2008 (DPM.12/6A Vol.1 (71) $8(21.1 \%)$ of the respondents, ISO 15489: Information and Documentation - Records Management 24(63.2\%) of the respondents, Kenya Police Standing Orders of 2001 none of the respondents understood the law, Government of Kenya Security Manual, 2005 9(23.7\%) of the respondents. This result shows the understanding of the respondents of the existing laws and statutes governing records management, and is varied based on the laws. A higher percentage (73\%) of the respondents understood the Public Archives and Documentation Service Act, Cap. 19, 1965 (Revised 2003) well. This tells of the greater effort the government needs to exert to enable the public and more so records managers to understand the importance of legal frameworks in records management. It is important that records managers understand all the laws applicable to electronic records management before developing or supporting the electronic records management strategy. Records managers also need to understand these laws before developing their records management policies and procedures.

\subsection{Permanent preservation}

Lin, Ramaiah and Wal (2013) explain the problems associated with huge volumes of information, storage media that are always changing, obsolescence of both hardware and software. The researchers wanted to understand the records in the agencies that may need to be kept permanently. 37(97.3\%) of the respondents agreed that there were records for permanent preservations. The respondents also indicated that their agencies had records which should be kept for over long periods of time. In this regard, $12(31.6 \%)$ of the respondents said 10 years; $9(23.6 \%) 50$ years while $15(39.5 \%)$ of the respondents said 100 years. The researchers wanted to know if there is a budget for such preservation activities as migration or conversion and $12(31.6 \%)$ said yes, $16(42.1 \%)$ did not think so and $8(21.1 \%)$ were not sure. The fact that most of the respondents said there were electronic records in their agencies for permanent preservation calls for better measures in preserving these records.

\subsection{Metadata}

While managing and using e-records, it is important to incorporate metadata to aid future retrieval of these records. Tough and Moss (2003) explains that the development and use of elaborate embedded directory structures or file plans, derived from functional analysis, should be a key component in the future development of the discipline of records management. Metadata makes up these elaborate embedded directory structure. The respondents identified metadata provided as mandatory or optional in their agency record keeping system. Mandatory metadata are agent 23(60.5\%), title 33(86.8\%), subject 33(86.8\%), description $27(71 \%)$, relation $12(31.5 \%)$, coverage $19(50 \%)$, function $25(65.7 \%)$, date $32(84.2 \%)$, format $24(63.1 \%)$, record identifier 30(78.9\%), and location 28(73.6\%).

\subsection{File formats}

The researchers sought to find out the specific file formats used to store official electronic records in the government agencies. The file formats were separated into text, graphics, video and audio and proprietary software programs; those that are supplied by the vendors. International Records Management Trust (n.d.) explains that

"A significant challenge for preserving electronic records is the degradation of the software or systems required to make digital information readable. Another difficult problem in preserving electronic records is the inevitable obsolescence of the technology used to create them."

It identifies PDF/A as one of the normalising formats for long-term preservation of the text formats but does not support video and audio formats. It also requires using software that conforms to ISO standard 19005-1. The respondents identified the text records they manage are PDF 37(97.3\%); TXT 8(21\%) and DOC 17(44.7\%). For graphics, the formats were identified as GIF 13(34.2\%); JPEG 28(73.6\%); and PNG 
7(18.4\%). For video and audio, the respondents identified MOV 5(13.1\%); MPEG 23(60.5\%); WMV 4(10.5\%); WAV 4(10.5\%); MP3 14(36.8\%); and AVI 6(15.7\%). The respondents also stated that they manage proprietary and software files such as data files $28(73.6 \%)$ and spread-sheets $13(34.2 \%)$.

\subsection{Digital media of storage}

The choice of digital media storage depends on the types of records one store, whether graphics, text, database, performance issues to consider; how well the current media meet the agency needs; and how fast the media can become obsolete. On the digital media of storage, 32(84.2\%) of the respondents said that hard disk was the digital media storage used by their agency; 7(14.4\%) used magnetic tapes; 4(10.5\%) used videotape; $10(26.3 \%)$ used CD-R disks; while 9(23.6\%) used DVD. It was observed that no respondent used flash disks perhaps because of their vulnerability to virus attacks and loss. The preference was given to the hard drive and magnetic media over optical and solid state by most agencies. This, however, requires that a proper policy and strategy be put in place to determine the best media for the long-term preservation of electronic records. The best storage conditions should also be considered for media longevity.

\section{Conclusion}

The Government of Kenya recognises electronic records as valuable. Indeed, it has developed and deployed several policies and legislation to enhance the management and use of electronic records to provide evidence of transactions and events for posterity. The respondents acknowledged being aware of and applying these policies and legislation in their day-to-day operations. They are specifically aware of records retention periods and schedules. The records managers in government agencies in Kenya are also aware of the standards regarding metadata, file formats, and record storage media. However, they decried lack of facilitative structural and budgetary provisions to implement these effectively.

\section{References}

Asogwa, B. E. (2012). The challenge of managing electronic records in developing countries: Implications for records managers in sub Saharan Africa. Records Management Journal, 22(3), 198-211. https://doi.org/10.1108/09565691211283156

Bellardo, T., \& Carlin, L. (1992). Glossary for archivists, manuscript curators, and records managers. Chicago: Society of American Archivists.

Duranti, L., \& MacNeil, H. (1996). The protection of the integrity of electronic records: an overview of the UBC-MAS research project. Archivaria, 42: 46-67. Available from: https://archivaria.ca/index.php/archivaria/article/viewFile/12153/13158 (Accessed 20 June 2018).

Electronic Records Management Guidelines, Digital Media. (n.d.). Retrieved June 19, 2018, from http://www.mnhs.org/preserve/records/electronicrecords/erdigital.php\#digital

European Commission. (2001). Requirements for the management of electronic records (MoReq Specification). Brussels, Luxemburg: Cornwell Affiliates.

Gilliland-Swetland, A. (2005). Electronic records management. Annual Review of Information Science and Technology, 39(1), 219-253.

Government of Kenya (2009). National policy on records management. Available from: http://www.archives.go.ke/wp-content/uploads/2016/10/NATIONAL-RECORDS-

MANAGEMENT-POLICY-10_04_2009.pdf. (Accessed 20 June 2018)

International Records Management Trust. (n.d.). Preserving Electronic Records.

Johnston, G. P., \& Bowen, D. V. (2005). The benefits of electronic records management systems: a general review of published and some unpublished cases. Records Management Journal, 15(3), 131140.

Lin, L. S., Ramaiah, C. K., \& Wal, P. K. (2013). Problems in the preservation of electronic records. Library Review. https://doi.org/10.1108/00242530310465924

Marutha, N. (2018). The application of legislative frameworks for the management of medical records 
in Limpopo Province, South Africa, The application of legislative frameworks for the management of medical records in Limpopo Province, South Africa. Information Development, 0266666918772006. https://doi.org/10.1177/0266666918772006

McLeod, J., \& Hare, C. (Eds.). (2005). Managing electronic records. Facet Publishing.

Mnjama, N. (2003). Archives and records management in Kenya: problems and prospects. Records Management Journal, 13(2), 91-101.

Open Government Partnership (2015). Records management. Available from: https://www.opengovpartnership.org/theme/records-management. (Accessed 20 June 2018)

Sanya, O. (2015). Problems faced in archives and records management in Kenya. Available from: http://networkbooks.co.ke/index.php/2015/09/01/problems-faced-in-archives-and-recordsmanagement-in-kenya/. (Accessed 20 June 2018).

Shepherd, E. (1994). Managing electronic records. Records Management Journal, 4(1), 39-49.

Spindler, R. P. (2009). Electronic records preservation. London: Taylor \& Francis Group.

Sprehe, J. T. (2002). Enterprise records management: Strategies and solutions. A White Paper prepared for Hummingbird Ltd.

Sprehe, J. T. (2005). The positive benefits of electronic records management in the context of enterprise content management. Government Information Quarterly, 22(2), 297-303.

Thurston, A. (2015). Managing Records and Information for Transparent, Accountable, and Inclusive Governance in the Digital Environment: Lessons from Nordic Countries. Washington DC: World Bank Group.

Tough, A., \& Moss, M. (2003). Metadata, controlled vocabulary and directories: electronic document management and standards for records management. Records Management Journal, 13(1), 24-31. https://doi.org/10.1108/09565690310465713 